\title{
Sirtuin 1 promotes the growth and cisplatin resistance of endometrial carcinoma cells: a novel therapeutic target
}

\author{
Ryoichi Asaka, Tsutomu Miyamoto, Yasushi Yamada, Hirofumi Ando, David Hamisi Mvunta, Hisanori Kobara and \\ Tanri Shiozawa
}

Sirtuin 1 (SIRT1), originally identified as a longevity gene, is induced by caloric restriction, and regulates various cellular functions including DNA repair, cell survival and metabolism via the deacetylation of target proteins such as histone and p53. These functions are considered to act dualistically as preventing or facilitating cancer. This study aimed to clarify the expression and role of SIRT1 in endometrial carcinoma. Because a high-calorie diet was a well-known risk factor for endometrial carcinoma, we first hypothesized that SIRT1 might be downregulated in normal endometrial glandular cells of obese women. However, no correlation was observed between the expression of SIRT1 and body mass index (BMI). In contrast, regardless of BMI, the immunohistochemical expression of SIRT1 was significantly higher in endometrial carcinoma (108 cases) than in normal endometria (60 cases) $(P<0.05)$, and its overexpression was associated with a shorter survival $(P<0.05)$. Our experiments in vivo revealed that SIRT1 accelerated the proliferation of endometrial carcinoma cell lines (HHUA, HEC151, and HEC1B). SIRT1 overexpression significantly enhanced the resistance for cisplatin and paclitaxel in HHUA cells. Although p53 is an important target protein for SIRT1, the selective SIRT1 inhibitor (EX527) significantly suppressed the proliferation and cisplatin resistance of three endometrial carcinoma cell lines regardless of the p53 mutation status. In addition, SIRT1 overexpression in HHUA cells accelerated tumor growth and cisplatin resistance in nude mice, and EX527 significantly suppressed the growth of tumors of HHUA and HEC1B cells. No adverse effect of EX527 was observed in these mice. In conclusion, SIRT1 is involved in the acquisition of the aggressive behavior associated with endometrial carcinoma, and the SIRT1 inhibitor, EX527, may be a useful agent for the treatment of this malignancy.

Laboratory Investigation (2015) 95, 1363-1373; doi:10.1038/labinvest.2015.119; published online 14 September 2015

The incidence of endometrial carcinoma has been correlated with an elevated body mass index (BMI). ${ }^{1}$ Several nutritional factors, such as obesity, a high-calorie diet, and low physical activity, have been identified as risk factors for this malignancy. ${ }^{2}$ The reasons for these factors have been explained in terms of peripheral estrogen production, ${ }^{3}$ stimulation of the insulin-like growth factor-1 receptor by insulin, ${ }^{4}$ and a decrease in the adiponectin/leptin ratio. ${ }^{5}$ However, the mechanisms underlying how obesity or a high-calorie diet leads to endometrial carcinoma are not fully understood.

Caloric restriction was previously demonstrated to prolong lifespan in various organisms. ${ }^{6,7}$ Sir (Silent information regulator) family genes were reported to be involved in longevity and the Sir2 mutant decreased the lifespan of yeast by $50 \% .^{8}$ Sirtuins (SIRT1-SIRT7) have been identified as the human homologues of Sir2 and may act as longevity genes. Sirtuin 1 (SIRT1) was found to be very similar to Sir2 and encoded one of the nicotinamide adenine dinucleotide (NAD)-dependent histone deacetylases. ${ }^{9}$ Several stresses such as caloric restriction are known to enhance the expression of SIRT1 in human cells. In addition, the increase in the NAD/ dihydronicotinamide adenine dinucleotide ratio induced by a decrease in energy production was shown to enhance the activity of SIRT1 $1{ }^{10}$ SIRT1 can suppress the transcription of target genes by the deacetylation of histone. Furthermore, SIRT1 can directly deacetylate target proteins and suppress their functions by inducing their degradation. ${ }^{11}$ Several molecules including p53 have been identified as the target genes or proteins of SIRT1. SIRT1 is known to be involved in various cellular functions, such as glucose metabolism, the regulation of cell proliferation, DNA repair, the suppression of cell death, and anti-oxidative stress effects, which suppress tumorigenesis and prolong cell survival in non-neoplastic cells. Accordingly, SIRT1 may be involved in the protection

Department of Obstetrics and Gynecology, Shinshu University School of Medicine, 3-1-1 Asahi, Matsumoto, Japan

Correspondence: Dr T Miyamoto, MD, PhD, Department of Obstetrics and Gynecology, Shinshu University School of Medicine, 3-1-1 Asahi, Matsumoto 390-8621, Japan. E-mail: tmiya@shinshu-u.ac.jp

Received 26 January 2015; revised 12 July 2015; accepted 13 July 2015 
against age-related pathogenesis, such as various types of cancers, diabetes, hepatic steatosis, and cardiovascular disease. $^{12}$ Therefore, our first hypothesis is that SIRT1 may be downregulated in normal endometrial glandular cells of obese women, and that downregulation of SIRT1 may be involved in facilitating endometrial carcinogenesis.

On the other hand, the oncogenic function of SIRT1 has also been reported in cancer. SIRT1 was found to be overexpressed in many cancers including colon and prostate cancers. ${ }^{13,14}$ The findings of these studies suggested that once cancer cells acquired the ability to produce SIRT1, the presumed function of SIRT1 may promote the survival of carcinoma cells. Therefore, our next hypothesis is that SIRT1 may be overexpressed in endometrial carcinoma cells and facilitate the survival of these cells.

In the present study, we immunohistochemically examined the expression of SIRT1 in normal endometria and endometrial carcinoma, and analyzed the function of SIRT1 in endometrial carcinoma cells in vitro and in vivo. We also investigated the efficacy of a SIRT1 inhibitor, EX527, in the treatment of endometrial carcinoma.

\section{MATERIALS AND METHODS}

\section{Samples for Immunohistochemistry}

A total of 108 formalin-fixed and paraffin-embedded tissue specimens of endometrial carcinoma, 24 endometrial hyperplasia, and 60 normal endometria obtained by hysterectomy or biopsy were selected from the pathology files of Shinshu University Hospital, and used for immunohistochemistry. Histological diagnoses were made by two or more pathologists in the Department of Laboratory Medicine of Shinshu University Hospital. Endometrial carcinomas were treated between 1996 and 2007 and body mass indices and follow-up survival data were known. According to the International Federation of Gynecology and Obstetrics classification (2008), ${ }_{15}^{15} 87$ patients had stages I and II, while 21 had stages III and IV. Histologically, all of the 108 carcinomas were endometrioid adenocarcinoma ( 68 were grade 1, 21 were grade 2 , and 19 were grade 3 ). The endometrial hyperplasia samples included eight simple, eight complex, and eight atypical hyperplasia. Normal endometria were classified into 16 proliferative phase, 21 secretory phase, and 23 postmenopausal atrophic endometria according to endometrial dating. ${ }^{16}$ Each tissue sample was used with the approval of the Ethics Committee of Shinshu University, after obtaining written consent from the patients.

\section{Immunohistochemistry and Evaluation}

Immunohistochemical staining was performed using the streptavidin-biotin-peroxidase complex method according to the manufacturer's instructions (Histofine MAX-PO kit; Nichirei, Tokyo, Japan). The primary antibody was rabbit monoclonal anti-SIRT1 (1:50; Epitomics, Burlingame, CA, USA). Regarding SIRT1 staining, $4-\mu \mathrm{m}$-thick sections were deparaffinized and boiled in $0.01 \mathrm{~mol} / \mathrm{l}$ citrate buffer ( $\mathrm{pH}$ 6.0) for $20 \mathrm{~min}$ in a $500 \mathrm{~W}$ microwave oven. They were then treated with $0.3 \%$ hydrogen peroxide and incubated with the primary antibody at $4{ }^{\circ} \mathrm{C}$ overnight. After the sections had been washed in phosphate-buffered saline, they were incubated with biotinylated anti-rabbit immunoglobulin G, treated with peroxidase-conjugated streptavidin, and stained with diaminobenzidine and $0.15 \%$ hydrogen peroxidase. Counterstaining was performed with hematoxylin. Staining with a rabbit IgGIsotype control antibody (Abcam, Cambridge, UK) was used as a negative control. Renal cell carcinoma was used as a positive control (Supplementary Figure 2A). Immunoreactivity was evaluated according to the percentage of positive cells observed, which was defined as similar or stronger staining than endothelial cells as an internal control, among 500 cells in five high-power fields by three independent reviewers (RA, TM and YY), and these results were described as a positivity index (PI) with a maximal score of 100 . The PIs of normal endometria were counted in the glandular epithelium, except for the surface epithelium. The significance of differences in PI among the histological grades was examined using Scheffe's test. The significance of differences in PI between other clinicopathological parameters was examined using the MannWhitney $U$-test. A $P$-value of $<0.05$ was considered significant. Cumulative survival was also analyzed using the Kaplan-Meier method. Because the 75 percentile of PI in carcinoma was 52.75 , we tentatively defined PI $=50$ as the reference point of SIRT1 overexpression. Cases were classified based on the expression of SIRT1 ( $\mathrm{PI} \geqslant 50$ vs $\mathrm{PI}<50)$, and differences in survival were then evaluated using the log-rank test.

\section{Cell Lines, Transfection of SIRT1 siRNA, or CDNA}

Normal endometrial glandular cells were extracted from surgical specimens with a previously described protocol. ${ }^{17}$ The endometrial carcinoma cell line, Ishikawa was kindly provided by Dr Nishida (Kasumigaura Medical Center, Ibaraki, Japan), HHUA was provided by the RIKEN BioResource Center (Ibaraki, Japan), HEC108, HEC151, and HEC265 were provided by the JCRB Cell Bank (Osaka, Japan), HEC1A, HEC1B, ECC1, AN3CA, KLE, and RL95-2 were purchased from the ATCC (Manassas, VA, USA). The expression of the SIRT1 protein in these endometrial carcinoma cell lines was examined by western blot analysis (Supplementary Figure 1A). All of the cell lines apparently expressed the SIRT1 protein. SIRT1-specific siRNA and scramble siRNA (as control), the plasmids containing SIRT1-cDNA, and an empty plasmid (as the control) were purchased from Origene (Rockville, MD, USA), and each was transfected into the cell lines using Lipofectamine 2000 (Life Technologies, Carlsbad, CA, USA) according to the manufacturer's instructions. SIRT1-specific siRNAs were used for HEC151, HEC1B, HHUA, ECC1 and Ishikawa. SIRT1cDNAs were used for HEC151, HEC1B, ECC1 and Ishikawa. The stable SIRT1-overexpressing HHUA (HHUA-SIRT1) was established by the transfection of SIRT1-cDNA and the isolation of colonies using neomycin. Control HHUA was 
established by the same techniques using empty vector. The effects of silencing and overexpressing of SIRT1 in all cell lines were confirmed by western blot and real-time reverse transcriptase PCR (RT-PCR) (Supplementary Figures 1B and C).

\section{Cell Cycle Analysis (Flow Cytometry)}

Cell cycle was analyzed by quantitation of DNA content using flow cytometry. In brief, cells were removed using tripsinEDTA solution from the culture dishes. Then, the cells were adjusted to $10^{6}$ cells $/ \mathrm{ml}$ using PBS containing $0.2 \%$ triton $\mathrm{X}-100$ and ribonuclease (RNase), stained with $1 \mu \mathrm{g} / \mathrm{ml}$ of propidium iodide, and detected the fluorescence in flow cytometry (BD FACS CANTO Becton, Dickinson and Company)(Measurement condition was $585 / 42 \mathrm{~nm}$ of fluorescence wavelength, and $488 \mathrm{~nm}$ of excitation wavelength).

\section{Ultraviolet (UV) Irradiation}

Cells were cultured on $60 \mathrm{~mm}$-dish to $60-70 \%$ confluency. Medium was replaced to PBS, and the culture dishes without lid were irradiated for $5 \mathrm{~min}$ by UV-C (around $254 \mathrm{~nm}$ wavelength) using a UV germicidal lamp. Cells were harvested $8 \mathrm{~h}$ after UV irradiation.

\section{Western Blotting}

Proteins extracted from cultured cells were subjected to western blot analysis, as described previously, ${ }^{18}$ using antibodies against human SIRT1 (rabbit-polyclonal; Cell Signaling, Danvers, MA, USA), p53 (mouse monoclonal; Cell Signaling), acetylated-p53 (which recognized acetylation at Lys382; rabbit-polyclonal; Cell Signaling), p21 (mouse monoclonal; Cell Signaling), phosphorylated Akt (pAkt) (rabbit-polyclonal; Cell Signaling), phosphorylated MAPK (pMAPK) (rabbit monoclonal; Cell Signaling), FOXO3A (rabbit monoclonal; abcam, Cambridge, UK) and $\beta$-actin (mouse monoclonal; BioMakor, Rehovot, Israel) as the primary antibody. The membranes were blotted with a primary antibody at $4{ }^{\circ} \mathrm{C}$ overnight and then incubated with a peroxidase-conjugated secondary antibody. Bound antibodies were visualized using the ECL western blot detection reagent (Amersham, Piscataway, NJ, USA).

\section{Assay of SIRT1 Activity}

Protein was extracted from the cells cultured on $60 \mathrm{~mm}$ dishes, and the deacetylase activity of SIRT1 was measured using SIRT1 Activity Assay Kit (Fluorometric) (abcam) according to the manufacturer's instructions.

\section{Assay for Cell Proliferation and Anticancer Drug Resistance (WST-1 assay)}

The PI3K inhibitor, wortmannin (Sigma-Aldrich, St Louis, MO, USA), was used to inhibit the PI3K pathway. The MEK 1/2 inhibitor, U0126 (Sigma-Aldrich), was used to inhibit the MAPK pathway. The inhibitory effect of wortmannin $(1 \mu \mathrm{M})$ and U0126 $(10 \mu \mathrm{M})$ was confirmed by western blotting
(Supplementary Figure 1D). The SIRT1 selective inhibitor, EX527 (Merck Millipore, Billerica, MA, USA) was used at functional concentrations as described previously. ${ }^{19}$ The anticancer drugs, cisplatin (CDDP) (Sigma-Aldrich) and paclitaxel (PTX) (Wako, Osaka, Japan), diluted with 5\% dimethylformamide (DMFA) and saline were added to the culture medium at various concentrations, and cell viability was measured after $72 \mathrm{~h}$.

Cell viability in the assay for proliferation or anticancer drug resistance was evaluated using the WST-1 reagent (Roche Diagnostics, Basel, Switzerland) according to the manufacturer's instructions. Briefly, cells were seeded onto 96-well plates. After culturing the cells under various conditions, the WST-1 reagent was added to the medium. After $2.5 \mathrm{~h}$, A450 wavelength was measured using the microplate reader, SYNERGY HT (BioTek, Winooski, VT, USA). Each result was obtained from three independent experiments with 16 replicates.

\section{Soft-Agar Colony Formation Assay}

Each $60 \mathrm{~mm}$ plate was prepared by adding $2 \mathrm{ml}$ of agar medium $(0.8 \mathrm{ml}$ of $1.25 \%$ agar and $1.2 \mathrm{ml}$ of $\mathrm{F} 12$ medium with $15 \%$ FBS. Five hundred cells of control HHUA or HHUA-SIRT1 were suspended in $1 \mathrm{ml}$ of F12 medium with $15 \%$ FBS and $0.33 \%$ agar and then layered on top of the hardened agar medium in each $60 \mathrm{~mm}$ plate. Plates were maintained at $37^{\circ} \mathrm{C}$ for 4 weeks. Colonies were stained with $0.04 \%$ crystal violet- $2 \%$ ethanol in PBS. The total number of stained colony in each $60 \mathrm{~mm}$ plate was counted by three independent reviewers (RA, TM and YY). Each result was obtained from three independent experiments with three replicates.

Real-Time Reverse Transcriptase PCR (Real-Time RT-PCR) Total RNA was extracted using the TRIzol reagent (Life Technologies) according to the manufacturer's instructions, and reverse-transcribed to cDNA for PCR using the PrimeScript RT-PCR Kit (Takara Bio, Shiga, Japan). Sequences of the SIRT1-specific primer sets were 5'-TCAGTGTCATGG TTCCTTTGC- $3^{\prime}$ for the forward primer and $5^{\prime}$-AATCTG CTCCTTTGCCACTCT- $3^{\prime}$ for the reverse primer (annealing $57^{\circ} \mathrm{C}$ ). Real-time quantitative PCR was performed using the Light Cycler 480 DNA SYBR Green I Master (Roche Diagnostics) in Light Cycler 480 system II (Roche Diagnostics) according to the manufacturer's instructions. The amplified efficiency of the SIRT1 primers used for real-time RT-PCR was 1.970. The expression of SIRT1 mRNA was quantitated using $\beta$-actin as an internal control gene. The sequences of the $\beta$-actin specific primer sets were $5^{\prime}$ GACAGGATGCAGAAGGAGATTACT-3' for the forward primer and 5'-TGATCCACATCTGCTGGAAGGT-3' for the reverse primer (annealing $56^{\circ} \mathrm{C}$ ). Each experiment for realtime RT-PCR was independently repeated five times with three replicates. 
a
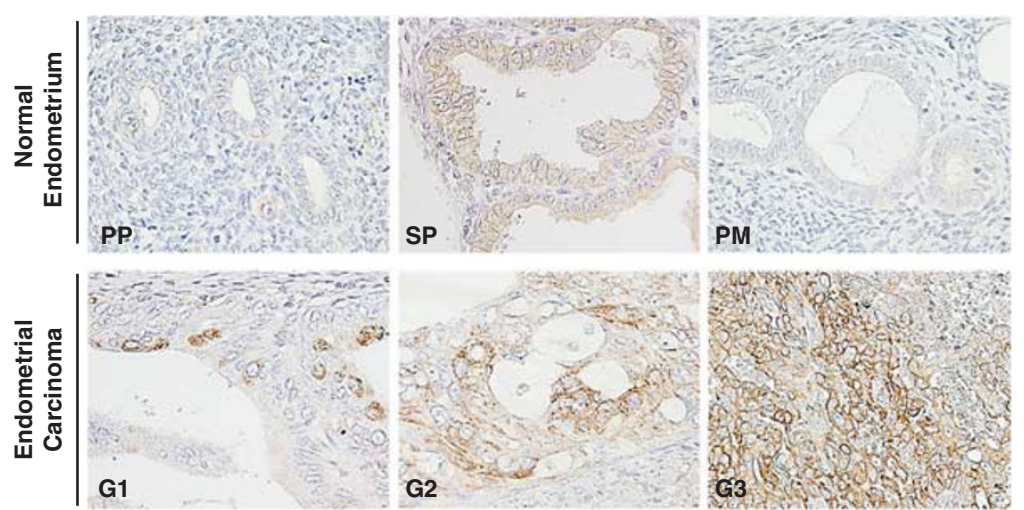

b

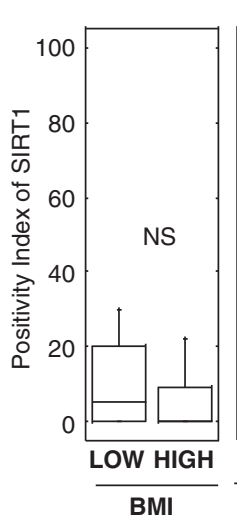

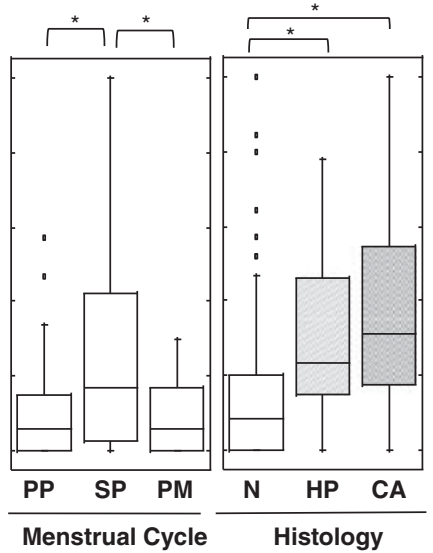

C

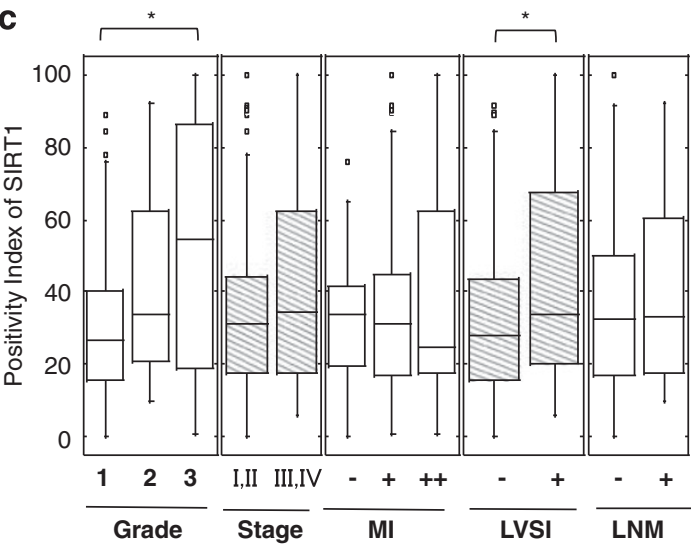

d
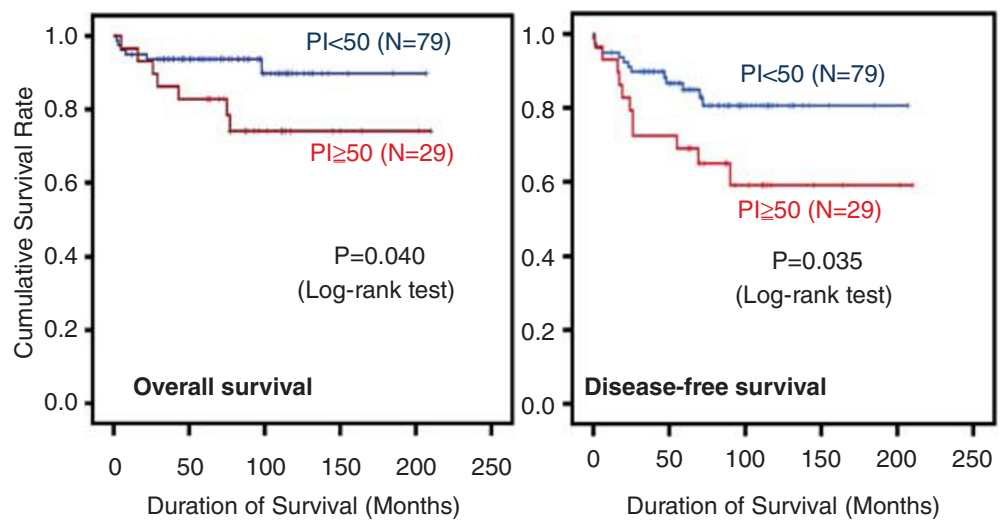

Figure 1 (a) Immunohistochemical staining for the SIRT1 protein in a normal endometrium (upper lane) and endometrial carcinoma (lower lane). (b) Positivity index (maximum score $=100$ ) in the groups classified by $\mathrm{BMI}$ (low: $\mathrm{BMI}<25$ and high: $\mathrm{BMI} \geqslant 25$ ), menstrual cycle, and histology. Box plot: box describes 25-75 percentiles. Lines in boxes show the median. Lines above/under the box show the maximum/minimum. Dots by circles are scores over $1.5 x \mathrm{IQR}$. ${ }^{*} P<0.05$, NS: No significant difference. (c) Pls in the clinicopathological status. ${ }^{*} P<0.05$. (d) Overall survival and disease-free survival of patients with $\mathrm{PI}<50$ and $\mathrm{PI} \geqslant 50$ using the Kaplan-Meier method. BMI, body mass index; CA, carcinoma; G1-3: endometrioid adenocarcinoma grades 1-3; HP, hyperplasia; IQR, interquartile range; LNM, lymph node metastasis; LVSI, lymph-vascular space invasion; MI, myometrial invasion (- negative, +positive in under half of the myometrium, ++ positive in over half of the myometrium); N, normal; NS, no significant difference;

$\mathrm{Pl}$, positivity index; PM, post-menopause; PP, proliferative phase; SP, secretory phase.

\section{Apoptosis Assay}

Immunofluorescent staining with propidium iodide and annexin-V (Annexin-V-FLUOS Staining Kit, Roche Applied Science) to detect apoptosis was performed according to the manufacturer's instructions. Pictures of cells were taken busing the Floid cell imaging station (Life Technologies). The cells stained with green color are indicating apoptotic cells. The number of green-colored cells was counted in three different fields under $\times 40$ magnification.

\section{p53 Sequencing}

The database for the $p 53$ gene status was obtained from the International Agency for Research on Cancer (IARC) TP53 Database (http://p53.iarc.fr). No data was available for ECC1 or RL95-2 in the Database. These two cell lines were examined using direct sequencing with the protocol and primer sets of IARC. Sequencing analysis was performed by an Applied Biosystems 130 genetic analyzer (Life Technologies)

\section{Assay of Tumor Growth in Nude Mouse}

The backs of 6-week-old nude mice (BALB/c-nu, Charles River Laboratories Japan, Kanagawa, Japan) were subcutaneously injected with $1 \times 10^{7}$ resuspended cells under anesthesia. The care and use of experimental animals was in accordance with the institutional guidelines. CDDP $(5 \mathrm{mg} / \mathrm{kg})$ and EX527 $(10 \mathrm{mg} / \mathrm{kg})$ were diluted with 5\% DMFA and saline, and were injected intraperitoneally every week. Mice in DMFA group (as control) were injected intraperitoneally with $400 \mu \mathrm{l}$ of 5\% DMFA and saline every week. The tumor size and body weight of each mouse were measured twice a week.

\section{Statistical Analysis}

Statistical analysis was conducted using the SPSS Statistics system (IBM, Armonk, NY, USA). 

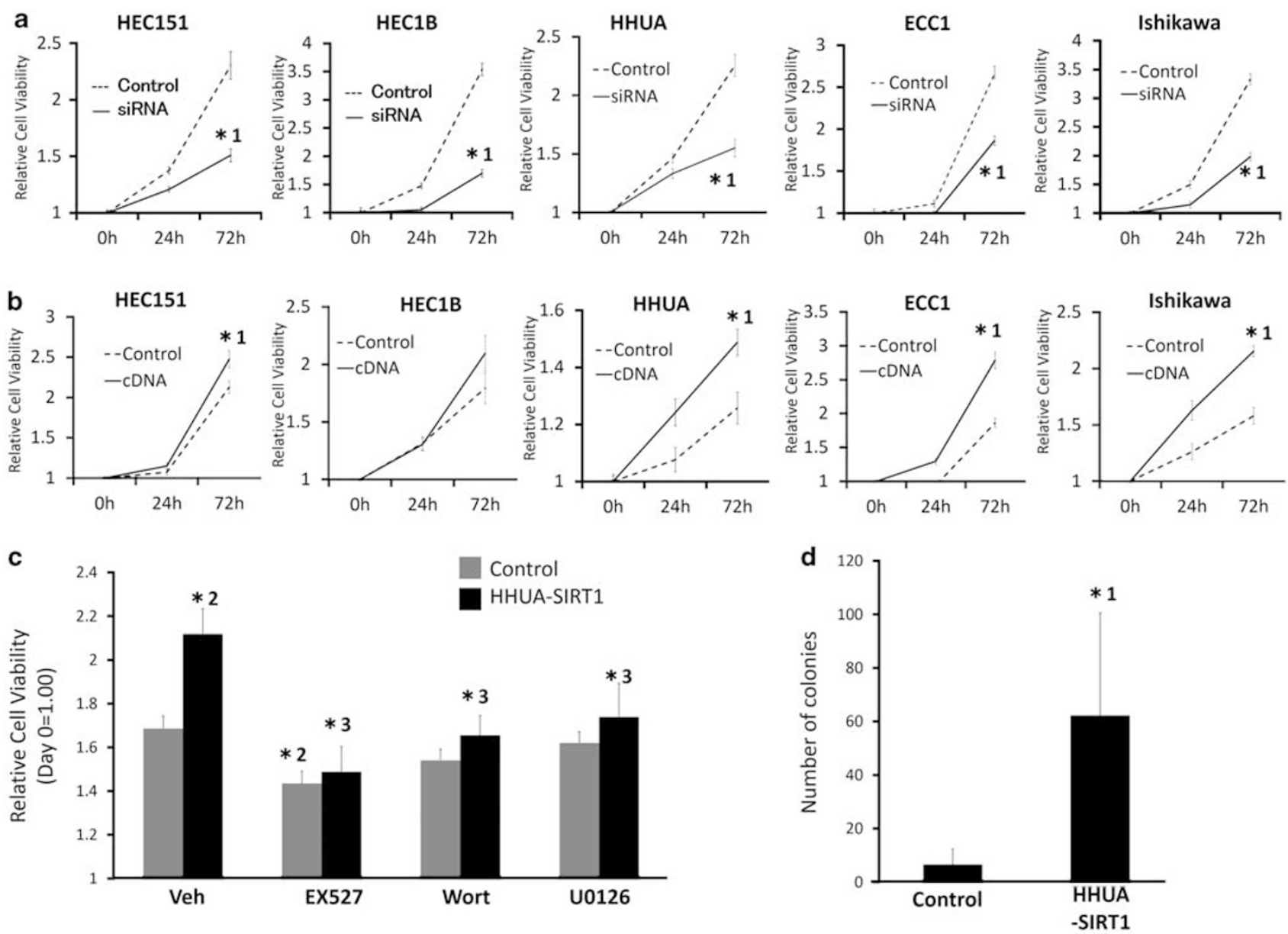

Figure 2 (a) Relative cell viabilities of endometrial carcinoma cell lines (HEC151, HEC1B, HHUA, ECC1, and Ishikawa) with SIRT1 silencing by SIRT1specific siRNA transfection (siRNA) or their control cells by scramble siRNA transfection (control). (b) Relative cell viabilities of endometrial carcinoma cell lines (HEC151, HEC1B, HHUA, ECC1, and Ishikawa) with SIRT1 overexpression by SIRT1 CDNA transfection (cDNA) or their control cells by empty vector transfection (control). (c) Relative cell viabilities of HHUA-SIRT1 and control cells when treated with the vehicle (Veh, 5\% DMFA as the solvent), EX527 (SIRT1 inhibitor: $1 \mu \mathrm{M}$ ), wortmannin (Wort, PI3K inhibitor: $1 \mu \mathrm{M}$ ), or U0126 (MEK inhibitor: $10 \mu \mathrm{M}$ ) for $24 \mathrm{~h}$. (d) The number of colonies formed by control HHUA and HHUA-SIRT1 were counted. ${ }^{*} 1$ : significantly different $(P<0.05)$ from control cells, ${ }^{*} 2$ : significantly different $(P<0.05)$ from control treated with Veh, *3: significantly different $(P<0.05)$ from HHUA-SIRT1 treated with Veh, but not different from control treated with the same agent. The error bars show the s.d. DMFA, dimethylformamide.

\section{RESULTS}

\section{The Immunohistochemical Expression of SIRT1 in} Normal and Neoplastic Endometria

The results of immunohistochemical staining for the SIRT1 protein were shown in Figure 1. Staining for SIRT1 was predominantly observed in glandular cells, but not in stromal cells (Figure 1a). The positive SIRT1 staining was predominantly localized in the cytoplasm. In normal endometria, the expression of the SIRT1 protein was significantly higher in the secretory phase than in the proliferative phase and postmenopausal endometria (Figure 1b). Among the three secretory phases, the expression of SIRT1 was only higher in the late secretory phase, which showed pre-decidual changes in the stroma (Supplementary Figure 2B). ${ }^{16}$ Contrary to our expectations, no correlation was observed between BMI and expression of the SIRT1 protein in normal endometrial glandular cells (Figure 1b). SIRT1 protein expression was significantly higher in endometrial carcinomas than in normal endometria (31.3 vs 8.5; median PI) (Figure $1 \mathrm{a}$ and b, Supplementary Figure 2C). However, no correlation was observed between the expression of SIRT1 in endometrial carcinomas and the BMI of patients (data not shown). The expression of SIRT1 was significantly elevated in patients with higher histological grades (54.5 as grade $3 v s 26.5$ as grade 1; median PI) and lymph-vascular space invasion (34.0 as positive $v s 28.0$ as negative; median PI) (Figure 1c). In addition, the overexpression of SIRT1 $(\mathrm{PI} \geqslant 50)$ aggravated overall survival $(P=0.040)$ and disease-free survival $(P=0.035)$ in endometrial carcinoma patients (Figure 1d). These results suggested that the expression of SIRT1 was associated with the aggressive behavior of endometrial carcinoma. 


\section{Effects of SIRT1 on Cell Proliferation}

The effect of SIRT1 on the proliferation of endometrial carcinoma cell lines was examined using the WST-1 assay. SIRT1 knockdown by SIRT1-specific siRNA significantly reduced the proliferative activities of HHUA, ECC1, Ishikawa, HEC1B and HEC151 cells $(P<0.05)$ (Figure 2a). In contrast, the proliferative activity of these cells with SIRT1 overexpression was stronger than that of control cells $(P<0.05)$ (Figure 2b). The result of flow cytometry indicated that S-phase fraction was increased by SIRT1 overexpression in HHUA cells $(13.7 \%$ of HHUA-SIRT1 vs $10.8 \%$ of HHUAControl) and decreased by SIRT1 knockdown in Ishikawa cells $(7.7 \%$ of Ishikawa-siRNA $v s 11.2 \%$ of Ishikawa-Control) (Supplementary Figures 4A and B). However, other changes in G1, G2 and sub-G1 fractions by alteration of SIRT1 expression were not observed in HHUA, ECC1, and Ishikawa cells. This effect SIRT1 overexpression on proliferation was canceled by the addition of a selective SIRT1 inhibitor (EX527), phosphoinositide 3-kinase (PI3K) inhibitor (Wortmannin), or mitogen-activated protein kinase (MAPK)/ extracellular signal-regulated kinase (ERK) kinase 1/2 (MEK 1/2) inhibitor (U0126) (Figure 2c). EX527 also decreased the viability of control HHUA cells $(P<0.05)$, whereas Wortmannin and U0126 could not decrease it. In addition, the colony formation assay using HHUA revealed that the number of colonies were increased by the overexpression of SIRT1 (Figure 2d). These results indicated that SIRT1 stimulated the proliferative activity of endometrial carcinoma cells. The PI3K and MAPK pathways might be involved in the part of SIRT1-induced cell proliferation.

\section{The Expression of SIRT1 Under Stresses}

Next, we focused on the effect of SIRT1 on cell survival. The expression of SIRT1 mRNA and protein in HHUA cells with cytotoxic treatment, such as ultraviolet (UV) and cisplatin (CDDP), was examined by real-time reverse transcriptase polymerase chain reaction (real-time RT-PCR) and western blotting. The expression of SIRT1 mRNA was increased by UV exposure $(150 \%$ increase, $P<0.05)$ (Figure $3 \mathrm{a}$ ) and CDDP treatment $(400 \%$ increase, $P<0.05)$ (Figure $3 b)$. The expression of SIRT1 protein was also increased by UV (Figure $3 a$ ) and CDDP (Figure 3b). In addition, the CDDP treatment increased the deacetylase activity of SIRT1 in endometrial carcinoma cells (Supplementary Figure 4C).

\section{Effects of SIRT1 on Anticancer Drug Resistance}

Because the immunoreactivity of recurrent tumors was higher for SIRT1 after platinum-based chemotherapy (Supplementary Figure $5 \mathrm{~A}$ ), the effects of SIRT1 on cell viability were examined in cells treated with an anticancer agent using the WST-1 assay. The results obtained revealed that the overexpression of SIRT1 significantly increased the viability of HHUA cells against CDDP (31\% increase compared with control under $20 \mu \mathrm{M}$ CDDP treatment, $P<0.05)$ and paclitaxel (PTX) (37 and 96\% increase compared with control under 2.5 and $5 \mu \mathrm{M}$ PTX treatment, respectively, $P<0.05$ ) (Figure 3c). This effect of SIRT1 on the CDDP resistance was cancelled by the SIRT1 inhibitor (EX527) (Figure 3d). EX527 additionally decreased the viability of both HHUA cells $(P<0.05)$. On the other hand, immunofluorescence for annexin- $V$ revealed that EX527 markedly increased apoptosis in both control HHUA and HHUA-SIRT1 with the CDDP treatment (Figure 4a, Supplementary Figure 5B). However, the PI3K inhibitor (Wortmannin) did not affect CDDP resistance or apoptosis (Figures 3d and 4a). U0126 also did not affect resistance or apoptosis (data not shown).

\section{CDDP Resistance by SIRT1 and p53}

A previous study demonstrated that $\mathrm{p} 53$ was one of the target proteins of deacetylation by SIRT $1{ }^{20}$ therefore, SIRT1induced CDDP resistance may be mediated via the inhibition of $\mathrm{p} 53$. The $\mathrm{p} 53$ inhibitor, cyclic pifithrin- $\alpha(\mathrm{CP} \alpha)$, was shown to decrease apoptosis in HHUA (Figure 4a), which confirmed the involvement of p53. The p53 gene mutation has frequently been reported in endometrial carcinomas ${ }^{21,22}$ and may influence the effects of SIRT1. Therefore, we examined the $p 53$ mutational status of 11 endometrial carcinoma cell lines by the International Agency for Research on Cancer (IARC) database or direct sequencing (Figure $4 \mathrm{~b}$, Supplementary Table 1). Of these, three cell lines had wildtype $p 53$ and eight cell lines had $p 53$ mutations. In the present study, we used five cell lines; HEC151 with wild-type $p 53$ and strong expression of p21, HHUA with a partially functional p53 mutation and detectable expression of p21, Ishikawa, ECC1 and HEC1B with a non-functional p53 mutation and undetectable expression of p21. In HEC151, Ishikawa and ECC1 cells, the addition of the SIRT inhibitor (EX527) and CDDP increased the expression of p53 acetylated at Lys382 (Figure 4c). These results identified p53 as the substantial target protein of SIRT1 in endometrial carcinoma cells.

The WST-1 assay revealed that EX527 significantly decreased the survival of HEC151 cells (with wild-type p53) with the CDDP treatment (45\% decrease from CDDP, $P<0.05)$, and the addition of $\mathrm{CP} \alpha$ partially recovered survival (18\% recovery from CDDP+EX527, $P<0.05$ ) (Figure 4d). EX527 significantly reduced CDDP resistance in HEC1B cells with mutated and non-functional p53 (18\% decrease from CDDP, $P<0.05)$. However, the addition of $\mathrm{CP} \alpha$ did not recover CDDP resistance (8\% decrease compared with CDDP+EX527 without significant difference). These results indicated that SIRT1 may act by enhancing CDDP resistance via p53-dependent and p53-independent pathways.

\section{Effects of SIRT1 and the SIRT1 Inhibitor on Tumor Growth in Nude Mice}

The effects of SIRT1 on tumor formation were examined in vivo using a mouse xenograft model of endometrial carcinoma cell lines. Four weeks after grafting, the size of HHUA-SIRT1 tumors was $~ 40 \%$ larger than that of control HHUA $(P<0.05)$ (Figure 5a and b). Hematoxylin-eosin $(\mathrm{HE})$ 

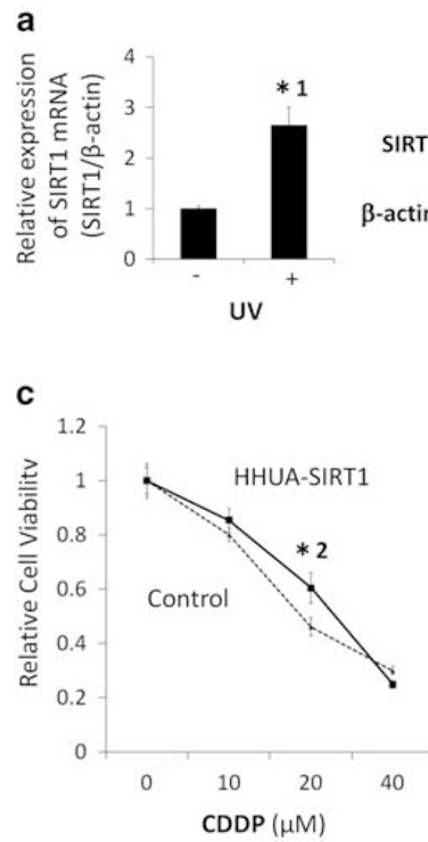
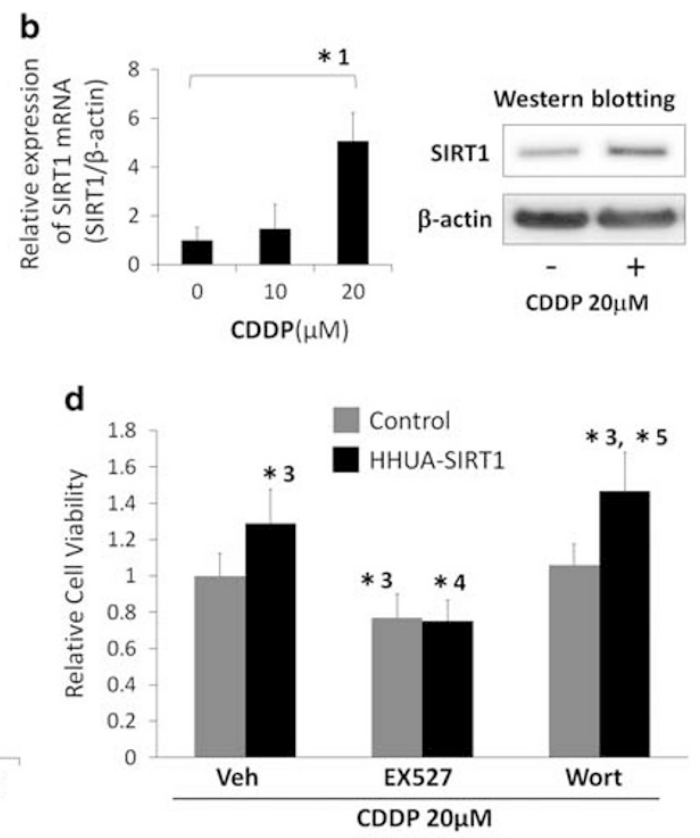

Figure 3 (a) Relative expression of SIRT1 mRNA (real-time reverse transcriptase PCR) and protein (western blotting) in HHUA cells with (+) or without $(-)$ ultraviolet (UV) exposure. (b) Relative expression of SIRT1 mRNA (real-time reverse transcriptase PCR) and protein (western blotting) in HHUA cells treated by $72 \mathrm{~h}$ with CDDP. (c) Relative cell viabilities of HHUA-SIRT1 and control cells treated with CDDP (0-40 $\mu \mathrm{M})$ and paclitaxel (PTX: 0-10 nM) for $72 \mathrm{~h}$. (d) Relative cell viabilities with the CDDP $(20 \mu \mathrm{M})$ treatment in HHUA-SIRT1 and control cells with the vehicle (Veh; $5 \%$ DMFA as the solvent), EX527 $(1 \mu \mathrm{M})$, or wortmannin (Wort; $1 \mu \mathrm{M})$ for $72 \mathrm{~h}$. ${ }^{*} 1$ : significantly different $(P<0.05)$ from no treatment, ${ }^{*} 2$ : significantly different $(P<0.05)$ from control cells, *3: significantly different $(P<0.05)$ from control treated with Veh, *4: significantly different $(P<0.05)$ from HHUA-SIRT1 treated with Veh, *5: significantly different $(P<0.05)$ from control treated with the same agent. The error bars show the s.d. CDDP, cisplatin; DMFA, dimethylformamide; PTX, paclitaxel.

staining revealed that HHUA-SIRT1 tumors were less necrotic than those of control HHUA (Figure 5c). In addition, immunofluorescent staining of the cleaved-caspase 3 protein showed apoptosis was less in HHUA-SIRT1 than in control HHUA (Figure 5c).

We then examined the effects of EX527 and CDDP in vivo using mouse xenografts. HHUA-SIRT1 tumors exhibited stronger resistance against the CDDP treatment than HHUA control tumors (Figure 6a). However, the treatment with EX527 markedly inhibited the tumor growth of HHUASIRT1 to the same level as that of control HHUA (Figure 6a). On the other hand, body weight gain was not impaired in mice, and no other adverse events were observed (Figure 6b) with the EX527 treatment. In addition, we confirmed the effects of EX527 on tumor growth in the p53 non-functional endometrial carcinoma cell line, HEC1B. The intraperitoneal infusion of EX527 significantly reduced the tumor growth of HEC1B (Figures $6 \mathrm{c}$ and d). These results indicated that EX527 could suppress the tumor growth of endometrial carcinoma regardless of the $p 53$ mutational status.

\section{DISCUSSION}

Obesity is a risk factor for endometrial carcinoma. ${ }^{23}$ SIRT1 was reported to be involved in the longevity induced by caloric restriction, ${ }^{10}$ and its function in DNA repair and control of the cell cycle ${ }^{24}$ was found to be similar to that of a tumor suppressor gene. Therefore, we first hypothesized that
SIRT1 may be downregulated in the normal or cancerous tissues of women with a high BMI. Contrary to this expectation, a correlation was not found between BMI and SIRT1 in the present study.

We also revealed that the expression of SIRT1 did not change in a normal cyclic endometrium or menopause, except for the late secretory phase. The effects of estrogen and progesterone are known to be evoked via their specific receptors, the estrogen receptor (ER) and progesterone receptor $(\mathrm{PR})$. We previously reported that the expression of ER and PR was significantly diminished in the late secretory phase of normal endometrial glandular cells. ${ }^{25}$ Therefore, the expression of SIRT1 in a normal endometrium does not appear to be controlled by sex steroids. However, the expression of SIRT1 was found to be upregulated by estrogen in a breast cancer cell line. ${ }^{26}$

The present study showed that the expression of SIRT1 was significantly higher in endometrial carcinomas than in normal endometrial glands. Its expression was also elevated in grade 3 tumors, and was associated with a shorter survival rate in endometrial carcinoma patients. Furthermore, this study revealed that SIRT1 stimulated the proliferation of endometrial carcinoma cells. These results suggest the oncogenic nature of SIRT1 in this malignancy. Although the overexpression of SIRT1 has already been reported in breast, lung, pancreas, colon, and prostate cancers $^{27-31}$ and has been associated with a poor prognosis, ${ }^{27-29}$ this is the first study 


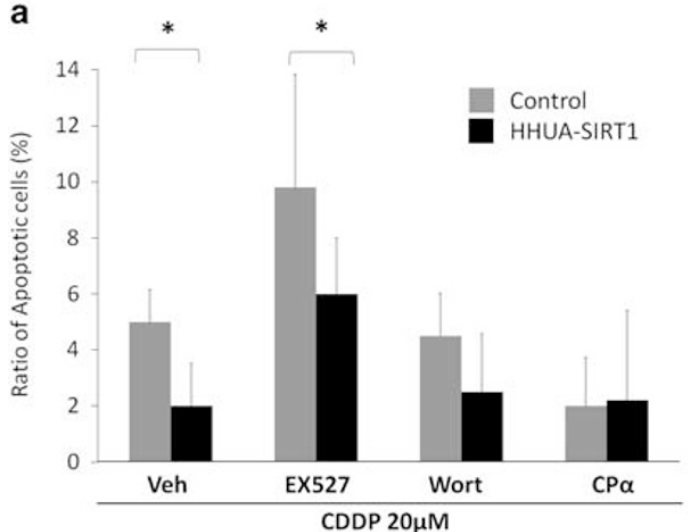

b

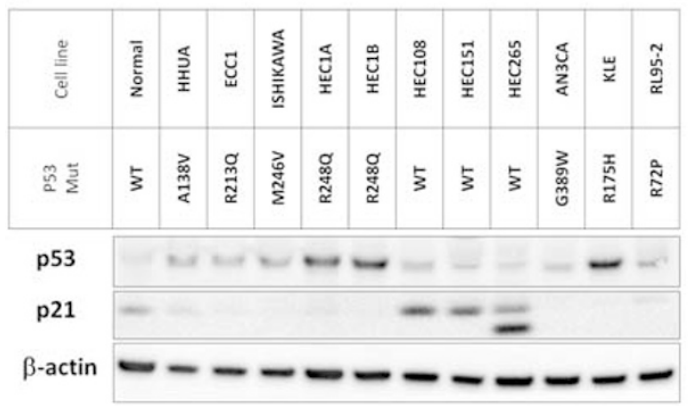

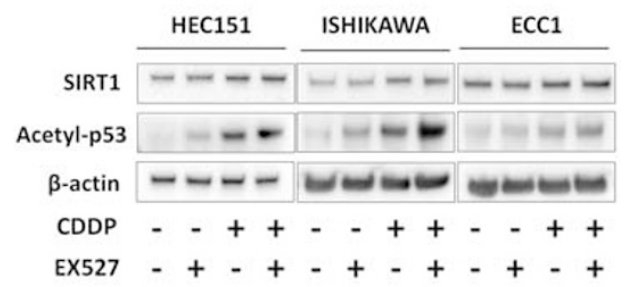

d

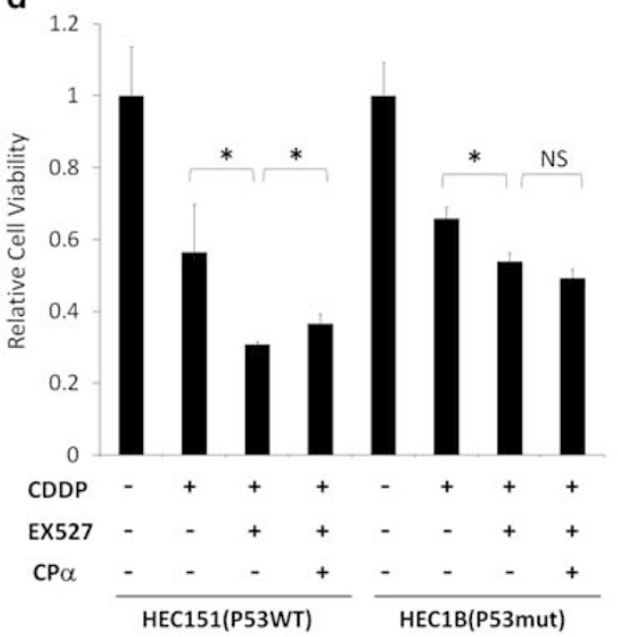

Figure 4 (a) Results of immunofluorescent staining for annexin-V and propidium iodide. HHUA-SIRT1 and control cells were treated with CDDP (20 $\mu \mathrm{M}$ ) and Veh (5\% DMFA as the solvent), EX527 $(1 \mu \mathrm{M})$, Wort $(1 \mu \mathrm{M})$, or Cyclic pifithrin- $a$ (CPa: p53 inhibitor, $10 \mu \mathrm{M})$ for $24 \mathrm{~h}$. Graph indicates the percentage of apoptotic cells evaluated by counting the green-colored cells. (b) Description of the p53 mutation and the expression of p53, p21, and $\beta$-actin (internal control) proteins in endometrial carcinoma cell lines and normal endometrial glandular cells (western blotting). (c) Western blot analysis for SIRT1, Acetyl-p53 (Lys 382), and $\beta$-actin (internal control) in HEC151, Ishikawa and ECC1 cells treated with/without EX527 (1 $\mu \mathrm{M})$ and CDDP (20 $\mu \mathrm{M}$ for HEC151 and Ishikawa, and $5 \mu \mathrm{M}$ for ECC1) for $24 \mathrm{~h}$. (d) Relative cell viabilities of HEC1B and HEC151 cells treated with/without CDDP (20 $\mu \mathrm{M})$, EX527 $(1 \mu \mathrm{M})$, and $\mathrm{CPa}(10 \mu \mathrm{M}) .{ }^{*} P<0.05$. The error bars show the s.d. NS: no significant difference. CDDP, cisplatin; DMFA, dimethylformamide.

to demonstrate the expression of SIRT1 in endometrial carcinoma.

We showed that SIRT1-induced cell proliferation was cancelled by the SIRT1 inhibitor (EX527), PI3K inhibitor (Wortmannin), and MEK inhibitor (U0126). The growth inhibition by Wortmannin and U0126 was smaller than that by EX527. These results suggested that the PI3K and MAPK pathways might be involved in the part of SIRT1-induced cell proliferation. Regarding the target molecule of SIRT1, PTEN (phosphatase and tensin homolog) and Akt were reported to be the subject of deacetylation by SIRT $1 .{ }^{32}$ The deacetylation of the Lys14 and Lys20 of Akt were necessary for the binding of Akt to PIP3 (phosphatidylinositol $(3,4,5)$-triphosphate) and for its membrane localization and activation. ${ }^{33}$ However, our results could not demonstrate the relation between the expression of pAkt or pMAPK and the expression of SIRT1.

We also revealed that SIRT1 increased resistance against CDDP or PTX in 3 endometrial carcinoma cell lines, which was consistent with the findings of a previous study on the effects of SIRT1 on anticancer drug resistance in other carcinomas. ${ }^{34}$ The p53 protein is known to be an important target of deacetylation by SIRT1. ${ }^{11,20}$ The DNA binding capacity of deacetylated p53 was previously shown to be reduced, ${ }^{35}$ which promoted MDM2-mediated ubiquitination and degradation. ${ }^{36}$ Therefore, $\mathrm{p} 53$ is considered to be a key factor in SIRT1-mediated survival in tumor cells with wildtype p53 such as HEC151. In addition, we showed that SIRT1-mediated CDDP resistance may be independent of the PI3K and MAPK pathways.

We also showed that EX527 significantly suppressed the CDDP resistance of endometrial carcinoma cells not only with wild-type $p 53$, but also those harboring mutated $p 53$. Apart from the p53-dependent pathway, the mechanism underlying SIRT1-mediated CDDP resistance is not well understood. However, the FOXO (forkhead box protein $\mathrm{O}$ ) family may be involved in SIRT1-mediated CDDP resistance. In tamoxifen-resistant breast cancer cells, SIRT1 boosted anticancer drug resistance by regulating the nuclear localization of the transcriptional factor, FOXO1, which induced the expression of multidrug resistance protein $2 .{ }^{37}$ The elevated expression of FOXO1 in HEC1B cells has been reported previously. ${ }^{38}$ Wang et al. ${ }^{39}$ demonstrated that SIRT1 deacetylated FOXO3, which, in turn, triggered apoptosis by upregulating the genes necessary for cell death, and facilitated 
a
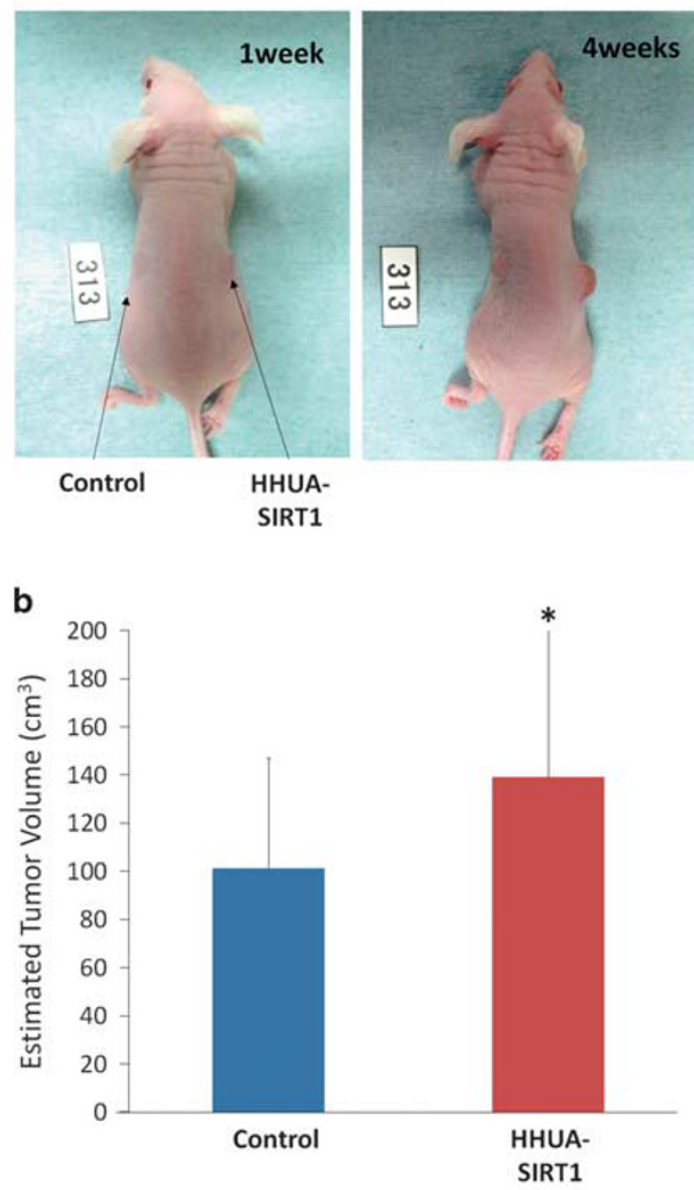

C
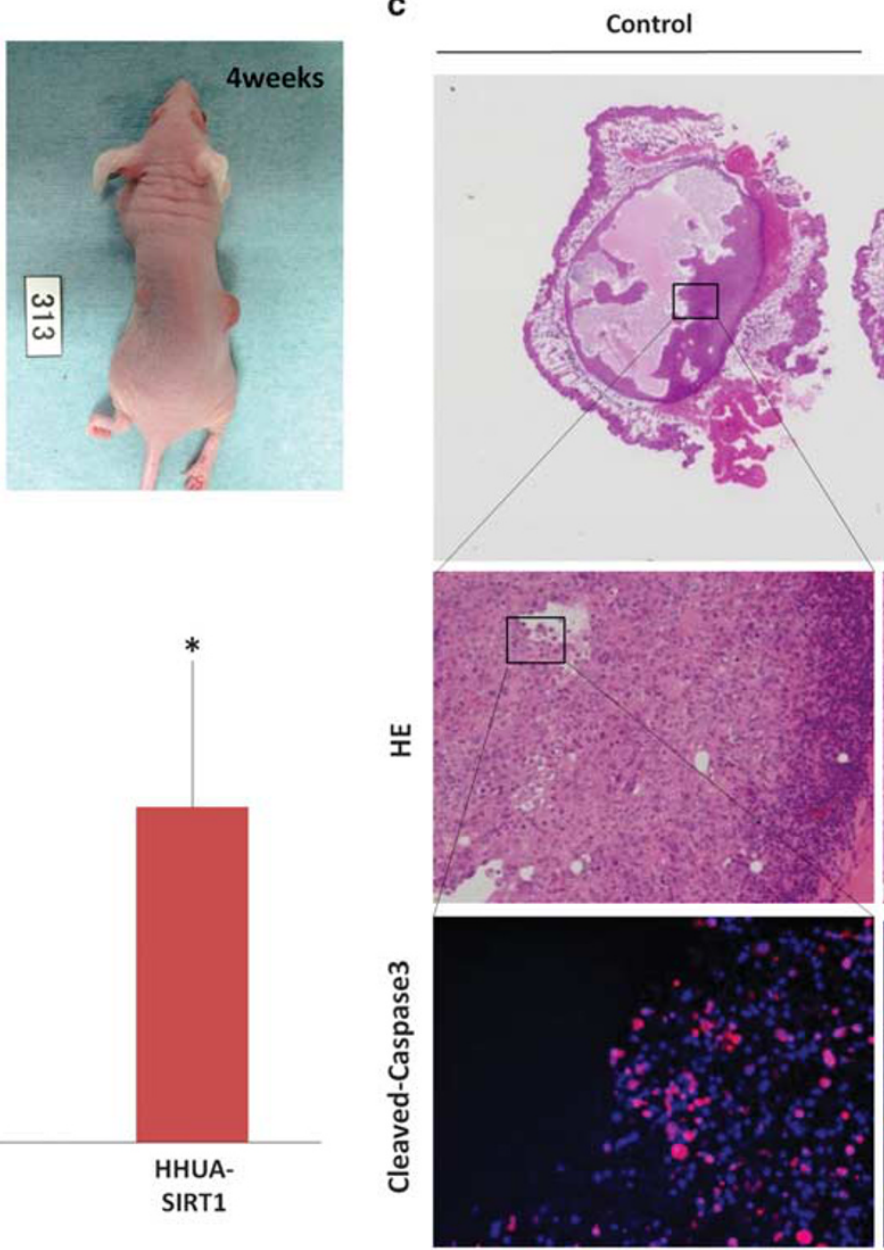
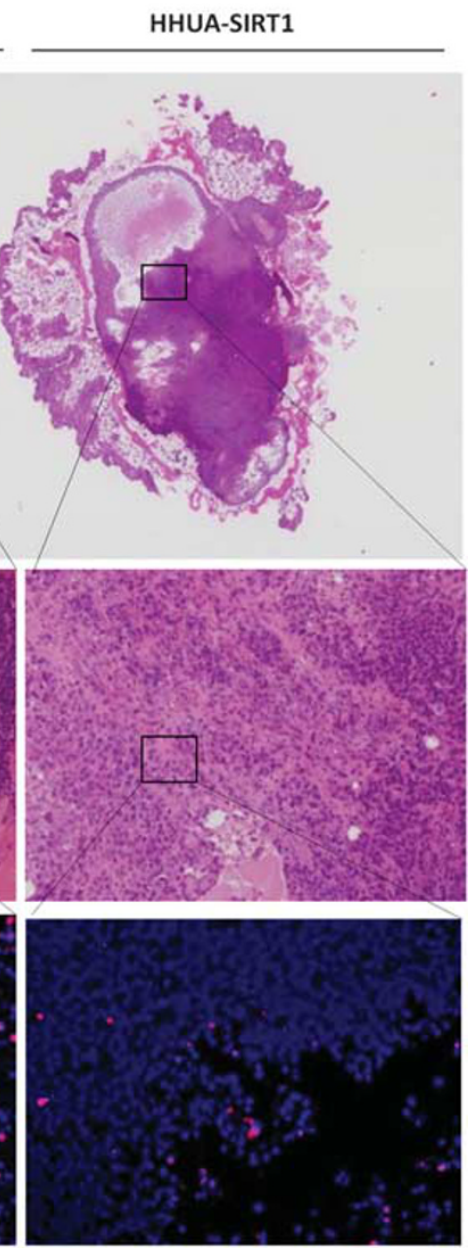

Figure 5 (a) HHUA-SIRT1 and control cells ( $10^{7}$ cells respectively) were subcutaneously grafted in nude mice (left dorsal: control, right dorsal: HHUASIRT1). (b) Estimated tumor volume of control and HHUA-SIRT1 4 weeks after grafting. Estimated tumor volume $=($ long axis $) \times(\text { short axis })^{2} \times 1 / 2\left(\mathrm{~cm}^{3}\right)$. (c) Control (left) and HHUA-SIRT1 (right) tumors were extracted from grafted mice. Upper lane: HE staining ( $\times 5)$. Middle lane: HE staining ( $\times 40)$. Lower lane: immunofluorescent staining for cleaved-caspase3 (red) and DAPI (blue) (x200). ${ }^{*} P<0.05$. The error bars show the s.d. NS: No significant difference. DAPI, 4',6-diamidino-2-phenylindole; HE, hematoxylin-eosin.

its degradation via poly-ubiquitination by the ubiquitinligase, Skp2 (S-phase kinase associated protein 2). The expression of FOXO3A protein was not changed by knockdown or overexpression of SIRT1 in our study. However, acetylation status of FOXO3A was not confirmed.

To date, no agent has demonstrated efficacy in moleculartargeted therapy against endometrial carcinoma. Our results indicated that SIRT1 may be a therapeutic target candidate. Several studies previously reported the anticancer effects of SIRT1 inhibitors. Ueno et al. ${ }^{40}$ showed that tenovin- 6 , an inhibitor of SIRT1 and 2, induced apoptosis in five colon carcinoma cell lines regardless of the p53 mutation status, and the synergistic antitumor effects of tenovin-6 were also observed in combination with either 5-FU or oxaliplatin. In contrast, Kabra et al. ${ }^{41}$ reported that EX527 $(2 \mu \mathrm{M})$, which is highly specific to SIRT1, but not SIRT2, enhanced the proliferation of the colon cancer cell line, HCT116. Peck et al. ${ }^{42}$ reported that $25 \mu \mathrm{M}$ or higher of Sirtinol and Salermide (inhibitors of SIRT1 and 2) significantly inhibited the proliferation of the breast cancer cell line, MCF-7, whereas $100 \mu \mathrm{M}$ or higher of EX527 repressed proliferation. These findings suggested that the inhibitors of SIRT1 and 2 had stronger anticancer effects than the selective SIRT1 inhibitor, EX527. However, the present study revealed that the lower dose $(1 \mu \mathrm{M})$ of EX527 significantly inhibited proliferation and had a synergic anticancer effect on CDDP chemotherapy in three endometrial carcinoma cell lines regardless of the $p 53$ mutation status. Zhang et al. ${ }^{43}$ also recently reported that EX527 $(1 \mu \mathrm{M})$ had significant anticancer effects in PANC-1 and ASPC-1 cell lines. In addition, our in vivo experiments demonstrated that EX527 significantly reduced the tumor growth of endometrial carcinoma in nude mice as a single agent. Therefore, EX527 appeared to be a more effective agent of molecular-targeted therapy for SIRT1, especially in endometrial carcinoma.

In contrast to the CDDP treatment, an intraperitoneal injection of EX527 (10 mg/kg/weekly for 4 weeks) did not promote adverse events or affect body weight gain in nude 

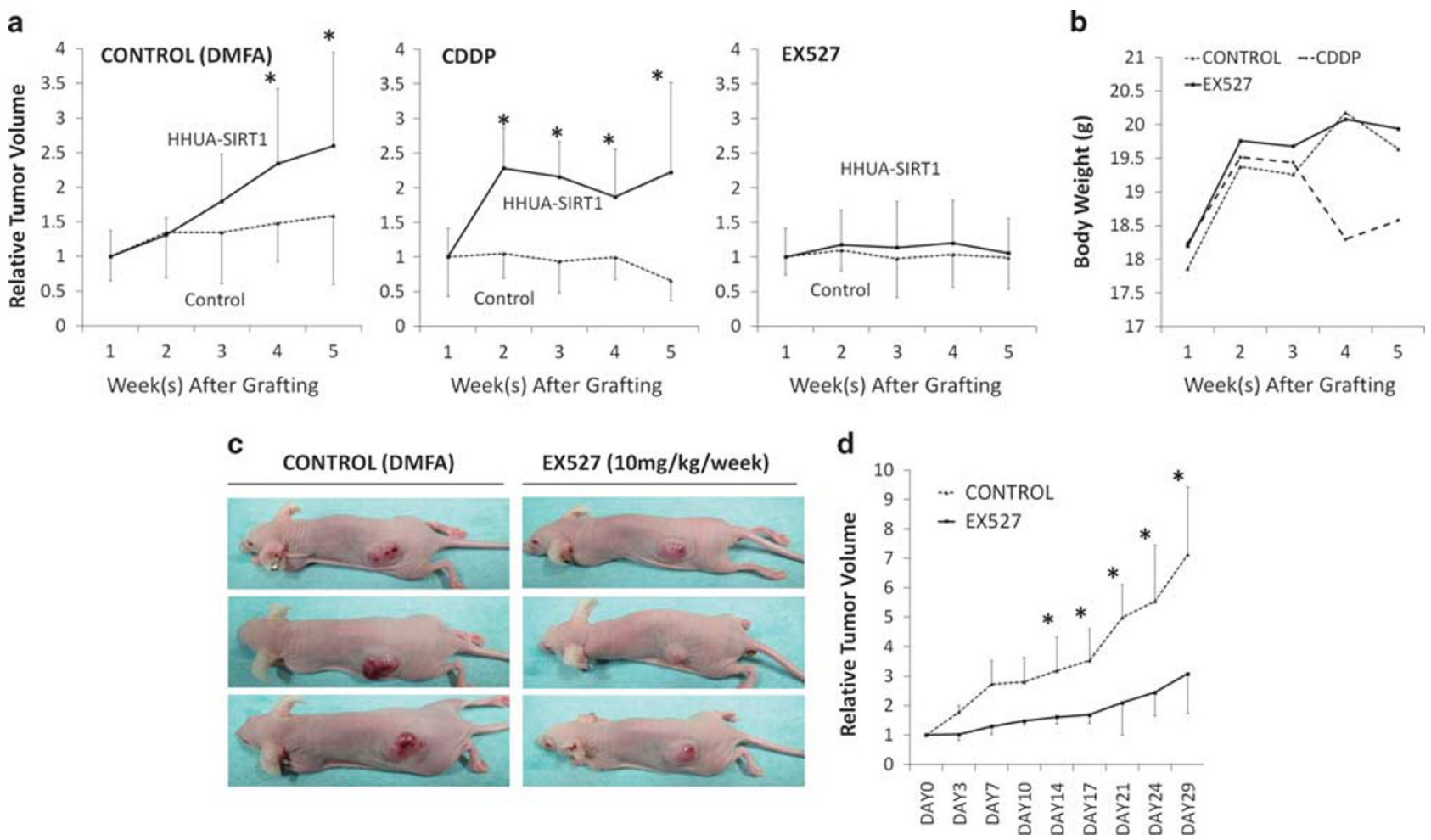

Figure 6 (a) Time-dependent changes in relative tumor volumes in nude mice treated with 5\% DMFA (as control), CDDP (5 mg/kg/weekly) or EX527 (10 mg/kg/weekly). (b) Body weight of each treatment group of mice. (c) HEC1B cells were subcutaneously grafted in nude mice. DMFA (left, as control) and EX527 (right, $10 \mathrm{mg} / \mathrm{kg} /$ weekly) were administrated. (d) Relative tumor volume of HEC1B treated with DMFA (black) and EX527 (blue). ${ }^{*} P<0.05$. The error bars show the s.d. NS: no significant difference. CDDP, cisplatin; DMFA, dimethylformamide.

mice. There were a few studies on the systemic administration of EX527 to mice, ${ }^{44,45}$ and no adverse effect of EX527 was noted. Among the other inhibitors of SIRT1 and 2, an intravenous injection (twice a week for 4 weeks) of sirtinol $(10 \mathrm{mg} / \mathrm{kg})$ and a daily intraperitoneal injection of cambinol $(100 \mathrm{mg} / \mathrm{kg})$ did not induce weight loss or adverse effects. ${ }^{46,47}$ However, serum glucose levels were not examined in this study. SIRT1 was previously reported to be involved in glucose metabolism due to the activation of AMPK (5' adenosine monophosphate-activated protein kinase), ${ }^{48}$ and also contributed to the regulation of serum glucose levels in type 2 diabetes mellitus. ${ }^{49}$ Therefore, further studies are needed to clarify the adverse effects associated with the administration of EX527, especially regarding metabolic disorders.

Our results showed that SIRT1 contributed tumor progression and chemoresistance of endometrial carcinoma. In addition, SIRT1 increased colony formation in soft agar. These findings suggest SIRT1 to provide stem cell nature to the cells. In breast cancer, CD44+/CD24- cancer stem cell had high level of SIRT $1 .^{50}$ However, there is no stem cell marker established in endometrial carcinoma.

In summary, the present study revealed that SIRT1 had important roles in tumor progression, growth, and anticancer drug resistance in endometrial carcinoma. The SIRT1 inhibitor effectively cancelled these functions of SIRT1 regardless of the $p 53$ mutation status. These results suggest that SIRT1 is a novel and promising therapeutic target candidate, and SIRT1 inhibitors especially EX527 may be useful agents for the treatment of endometrial carcinoma.

Supplementary Information accompanies the paper on the Laboratory Investigation website (http://www.laboratoryinvestigation.org)

\section{ACKNOWLEDGMENTS}

The authors are grateful to Fumi Tsunoda and Eiji Uchida (Research Assistants; Department of Obstetrics and Gynecology, Shinshu University School of Medicine) for their excellent technical assistance. This work was supported by JSPS KAKENHI grant number 24791696.

\section{DISCLOSURE/CONFLICT OF INTEREST}

The authors declare no conflict of interest.

1. Renehan $A G$, Tyson $M$, Egger $M$ et al. Body-mass index and incidence of cancer: a systematic review and meta-analysis of prospective observational studies. Lancet 2008;371:569-578.

2. Goodman MT, Hankin JH, Wilkens LR et al. Diet, body size, physical activity, and the risk of endometrial cancer. Cancer Res 1997;57: 5077-5085.

3. Berstein LM, Tchernobrovkina AE, Gamajunova VB et al. Tumor estrogen content and clinico-morphological and endocrine features of endometrial cancer. J Cancer Res Clin Oncol 2003;129:245-249.

4. Hirano S, Ito N, Takahashi $\mathrm{S}$ et al. Clinical implications of insulin-like growth factors through the presence of their binding proteins and receptors expressed in gynecological cancers. Eur J Gynaecol Oncol 2004;25:187-191. 
5. Petridou E, Mantzoros C, Dessypris N et al. Plasma adiponectin concentrations in relation to endometrial cancer: a case-control study in Greece. J Clin Endocrinol Metab 2003;88:993-997.

6. Viswanathan M, Guarente L. Regulation of Caenorhabditis elegans lifespan by sir-2.1 transgenes. Nature 2011;477:E1-E2.

7. Weindruch R. The retardation of aging by caloric restriction: studies in rodents and primates. Toxicol Pathol 1996;24:742-745.

8. Kaeberlein M, McVey M, Guarente L. The SIR2/3/4 complex and SIR2 alone promote longevity in Saccharomyces cerevisiae by two different mechanisms. Genes Dev 1999;13:2570-2580.

9. North BJ, Verdin E. Sirtuins: Sir2-related NAD-dependent protein deacetylases. Genome Biol 2004;5:224.

10. Lin SJ, Defossez PA, Guarente L. Requirement of NAD and SIR2 for lifespan extension by calorie restriction in Saccharomyces cerevisiae. Science 2000;289:2126-2128.

11. Vaziri $\mathrm{H}$, Dessain $\mathrm{SK}, \mathrm{Ng}$ Eaton $\mathrm{E}$ et al. hSIR2(SIRT1) functions as an NAD-dependent p53 deacetylase. Cell 2001;107:149-159.

12. Herranz D, Serrano M. SIRT1: recent lessons from mouse models. Nat Rev Cancer 2010;12:819-823.

13. Stünkel W, Peh BK, Tan YC et al. Function of the SIRT1 protein deacetylase in cancer. Biotechnol J 2007;2:1360-1368.

14. Lee H, Kim KR, Noh SJ et al. Expression of DBC1 and SIRT1 is associated with poor prognosis for breast carcinoma. Hum Pathol 2011;42: 204-213.

15. Pecorelli S. Revised FIGO staging for carcinoma of vulva, cervix, and endometrium. Int J Gynaecol Obstet 2009;105:103-104.

16. Noyes RW, Hertig AT, Rock J. Dating the endometrial biopsy. Am J Obstet Gynecol 1975;122:262-263.

17. Shiozawa $\mathrm{T}$, Miyamoto $\mathrm{T}$, Kashima $\mathrm{H}$ et al. Estrogen-induced proliferation of normal endometrial glandular cells is initiated by transcriptional activation of cyclin D1 via binding of c-Jun to an AP-1 sequence. Oncogene 2004;23:8603-8610.

18. Miyamoto T, Kashima H, Suzuki A et al. Laser-captured microdissectionmicroarray analysis of the genes involved in endometrial carcinogenesis: stepwise up-regulation of lipocalin2 expression in normal and neoplastic endometria and its functional relevance. Hum Pathol 2011;42:1265-1274.

19. Napper AD, Hixon J, McDonagh T et al. Discovery of indoles as potent and selective inhibitors of the deacetylase SIRT1. J Med Chem 2005;48: 8045-8054.

20. Luo J, Nikolaev AY, Imai S et al. Negative control of p53 by Sir2alpha promotes cell survival under stress. Cell 2001;107:137-148.

21. Risinger Jl, Dent GA, Ignar-Trowbridge $D$ et al. p53 gene mutations in human endometrial carcinoma. Mol Carcinog 1992;5:250-253.

22. Feng $Y Z$, Shiozawa $T$, Horiuchi $A$ et al. Intratumoral heterogeneous expression of p53 correlates with p53 mutation, $\mathrm{Ki}-67$, and cyclin A expression in endometrioid-type endometrial adenocarcinomas. Virchows Arch 2005;447:816-822.

23. Wynder EL, Escher GC, Mantel N. An epidemiological investigation of cancer of the endometrium. Cancer 1966;19:489-520.

24. Brachmann CB, Sherman JM, Devine SE et al. The SIR2 gene family, conserved from bacteria to humans, functions in silencing, cell cycle progression, and chromosome stability. Genes Dev 1995;9: 2888-2902.

25. Shiozawa T, Li SF, Nakayama $\mathrm{K}$ et al. Relationship between the expression of cyclins/cyclin-dependent kinases and sex-steroid receptors/Ki67 in normal human endometrial glands and stroma during the menstrual cycle. Mol Hum Reprod 1996;2:745-752.

26. Elangovan S, Ramachandran S, Venkatesan N et al. SIRT1 is essential for oncogenic signaling by estrogen/estrogen receptor $a$ in breast cancer. Cancer Res 2011;71:6654-6664.

27. Wu M, Wei W, Xiao X et al. Expression of SIRT1 is associated with lymph node metastasis and poor prognosis in both operable triplenegative and non-triple-negative breast cancer. Med Oncol 2012;29: 3240-3249.
28. Noh SJ, Baek HA, Park HS et al. Expression of SIRT1 and cortactin is associated with progression of non-small cell lung cancer. Pathol Res Pract 2013;209:365-370.

29. Stenzinger A, Endris V, Klauschen F et al. High SIRT1 expression is a negative prognosticator in pancreatic ductal adenocarcinoma. BMC Cancer 2013;13:450.

30. Kriegl L, Vieth M, Kirchner T et al. Up-regulation of c-MYC and SIRT expression correlates with malignant transformation in the serrated route to colorectal cancer. Oncotarget 2012;3:1182-1193.

31. Huffman DM, Grizzle WE, Bamman MM et al. SIRT1 is significantly elevated in mouse and human prostate cancer. Cancer Res 2007;67: 6612-6618.

32. Ikenoue T, Inoki K, Zhao B et al. PTEN acetylation modulates its interaction with PDZ domain. Cancer Res 2008;68:6908-6912.

33. Sundaresan NR, Pillai VB, Wolfgeher D et al. The deacetylase SIRT1 promotes membrane localization and activation of Akt and PDK1 during tumorigenesis and cardiac hypertrophy. Sci Signal 2011;4:ra46.

34. Wang Z, Chen W. Emerging Roles of SIRT1 in Cancer Drug Resistance. Genes Cancer 2013;4:82-90.

35. Kim EJ, Kho JH, Kang MR et al. Active regulator of SIRT1 cooperates with SIRT1 and facilitates suppression of p53 activity. Mol Cell 2007;28: 277-290.

36. Li M, Luo J, Brooks CL et al. Acetylation of p53 inhibits its ubiquitination by Mdm2. J Biol Chem 2002;277:50607-50611.

37. Choi HK, Cho KB, Phuong NT et al. SIRT1-mediated FoxO1 deacetylation is essential for multidrug resistance-associated protein 2 expression in tamoxifen-resistant breast cancer cells. Mol Pharm 2013;10: 2517-2527.

38. Goto $\mathrm{T}$, Takano M, Albergaria $\mathrm{A}$ et al. Mechanism and functional consequences of loss of FOXO1 expression in endometrioid endometrial cancer cells. Oncogene 2008;27:9-19.

39. Wang F, Chan C-H, Chen K et al. Deacetylation of FOXO3 by SIRT1 or SIRT2 leads to Skp2-mediated FOXO3 ubiquitination and degradation. Oncogene 2012;31:1546-1557.

40. Ueno T, Endo $\mathrm{S}$, Saito $\mathrm{R}$ et al. The sirtuin inhibitor tenovin-6 upregulates death receptor 5 and enhances cytotoxic effects of 5-Fluorouracil and oxaliplatin in colon cancer cells. Oncol Res 2014;21:155-164.

41. Kabra N, Li Z, Chen L et al. SirT1 is an inhibitor of proliferation and tumor formation in colon cancer. J Biol Chem 2009;284:18210-18217.

42. Peck B, Chen CY, Ho KK et al. SIRT inhibitors induce cell death and p53 acetylation through targeting both SIRT1 and SIRT2. Mol Cancer Ther 2010;9:844-855.

43. Zhang JG, Hong DF, Zhang CW et al. Sirtuin 1 facilitates chemoresistance of pancreatic cancer cells by regulating adaptive response to chemotherapy-induced stress. Cancer Sci 2014;105:445-454.

44. Oon CE, Strell C, Yeong KY et al. SIRT1 inhibition in pancreatic cancer models: contrasting effects in vitro and in vivo. Eur J Pharmacol 2015;757:59-67.

45. Yang $Y$, Jiang $S$, Dong $Y$ et al. Melatonin prevents cell death and mitochondrial dysfunction via a SIRT1-dependent mechanism during ischemic-stroke in mice. J Pineal Res 2015;58:61-70.

46. Gong DJ, Zhang JM, Yu M et al. Inhibition of SIRT1 combined with gemcitabine therapy for pancreatic carcinoma. Clin Interv Aging 2013;8:889-897.

47. Laemmle A, Lechleiter A, Roh V et al. Inhibition of SIRT1 impairs the accumulation and transcriptional activity of HIF-1a protein under hypoxic conditions. PLoS One 2012;7:e33433.

48. Suchankova G, Nelson LE, Gerhart-Hines Z et al. Concurrent regulation of AMP-activated protein kinase and SIRT1 in mammalian cells. Biochem Biophys Res Commun 2009;378:836-841.

49. Milne JC, Lambert PD, Schenk $\mathrm{S}$ et al. Small molecule activators of SIRT1 as therapeutics for the treatment of type 2 diabetes. Nature 2007:450:712-716.

50. Ma W, Xiao GG, Mao J et al. Dysregulation of the miR-34a-SIRT1 axis inhibits breast cancer stemness. Oncotarget 2015;6:10432-10444. 